\title{
Barbarians in Our Midst: 'Cultural Diversity' on the Transnational Internet
}

Uta Kohl [1]

Cite as: Kohl, U., "Barbarians in Our Midst: 'Cultural Diversity' on the Transnational Internet.", In European Journal of Law and Technology, Vol 5., No. 1., 2014.

\begin{abstract}
Much has been written on jurisdictional problems arising out of the transnationality of the internet in various legal fields. This article approaches this jurisprudence from an angle that emphasises the underlying substance of the concerns - by joining it with the quite separate discourse on 'cultural diversity' in the age of globalisation. The discussion comes partly as a response to those who believe that legal harmonisation is, or would be, impracticalities aside, the Holy Grail to many online regulatory problems. It is not. At the same time, the retention of 'cultural diversity' and its implicit endorsement by States in the face of the 'threat' of online globality is not unproblematic either. The article charts ostensibly very disparate legal subject areas and jurisprudential concerns to construct a narrative on how pre-internet incidents of globalisation (i.e. trade liberalisations in the EU and under the WTO as well as the creation of universal human rights) that triggered the emergence of 'cultural diversity' as a distinct value protected by various legal concepts and regimes, are continued and discontinued by the full-on online confrontation with 'Otherness'. Using child protection as a case study, because it brings to the fore substantial cultural and legal divergence even amongst European States, the discussion documents how States have responded to the online clashes with their distinct law spaces and the serious legitimacy concerns to which these responses are giving rise. The arguments extend to most other legal subject-matter challenged by online transnationality (e.g. various areas of criminal law, but also data protection or defamation law and even commercial areas such as copyright law).
\end{abstract}

\section{Introduction}

Jared Diamond in his book The World Until Yesterday (2012) [2] reflects on varying child rearing practices and observes that children in many traditional hunter-gatherer and smallscale societies are permitted to do dangerous things with the expectation that they will learn from their mistakes. Individual autonomy generally, and child autonomy in particular, enjoy a much higher status than in state societies. [3] For example, the 'Piraha Indians consider children just as human beings, not in need of coddling or special protection.... Citizens of the Piraha nation know that each day's survival depends on their individual 
skills and hardiness... The Pirahas' view that children are equal citizens of society means that there is no prohibition that applies to children but does not equally apply to adults.' [4]

This article argues that the internet confronts us with the values of other societies to an unprecedented level, and examines the possible and actual regulatory responses to that confrontation. The discussion taps into the debate on jurisdiction in the context of online transnationality but it approaches the issue not frontally, but from the side - by joining it with the jurisprudence on 'cultural diversity' which has emerged as a counterweight to various forms of globalisation. The article takes up this line of inquiry and revisits the 'tension between globalism and localism' [5] in the context of the internet. The internet has globalised communications as no media before it and exposes us to foreign value systems: how does this confrontation affect 'cultural identity'? How do States deal with online diversity and the Otherness coming from beyond their borders? These questions touch upon the critical legal discussion on the socio-cultural and legal construction of 'harm' as well as the body of literature on Otherness (or alterity) explored in anthropology, sociology, geography and politics. [6] The latter build on the ideas of the French philosopher Emmanuel Lévinas, [7] as captured by Simone de Beauviour in The Second Sex (1949):

'The category of the Other is as primordial as consciousness itself. In the most primitive societies, in the most ancient mythologies, one finds the expression of a duality - that of the Self and the Other. This duality was not originally attached to the division of the sexes; it was not dependent upon any empirical facts. It is revealed in such works as that of Granet on Chinese thought and those of Dumézil on the East Indies and Rome. The feminine element was at first no more involved in such pairs as Varuna-Mitra, Uranus-Zeus, SunMoon, and Day-Night than it was in the contrasts between Good and Evil, lucky and unlucky auspices, right and left, God and Lucifer. Otherness is a fundamental category of human thought.' [8]

The focus of this article is on the legal Other, i.e. individuals acting in accord with the laws of their land, as constructed through the creation of the nation state as a distinct legal unit on the international level. [9] The assumption behind the discussion of the legal Other is that legal differences are not arbitrary but meaningful and externalise, even in areas of seemingly neutral law e.g. on commercial activity, deep-rooted socio-cultural and political differences.

The case study for the discussion is child protection (although the general issues are as wide-ranging as online legalities) because, firstly, the thematic of childhood is as universal as its content is diverse. We need not go as far as the Piraha Indians to encounter immense differences about good parenting and the nature of appropriate 'higher' interference by the State and about the concept of childhood and its boundaries - even within historically close and culturally relatively homogenous peoples as in Europe. Second and interrelated, the protection of children from the dangers of, and exploitation through and for, the adult online environment has remained a stronghold of legal contestability. Regulators across the globe have struggled with accommodating competing interests even within their own jurisdiction and the resultant compromises have varied depending on the relative weight attached to child protection vis-à-vis other values. One background assumption here is that child welfare, albeit of great importance, is not and should not be the paramount value for ordering society but must be balanced against other competing public goods which are also essential for human thriving and democracy. So implementing compulsory filtering software at the level of ISPs or search engines or introducing compulsory internet passports 
as a surveillance mechanism would go towards reducing the exposure of children to unsavoury online material/people, but such measures also have major consequences for other core values, such privacy or free speech. How exactly the balance is or should be struck varies from society to society, depending on its attitude to risk, personal autonomy and individual freedoms as well as to state paternalism and childhood.

In short, online child protection is an issue very close to most societies' heart that touches upon their moral fabric and core values, and thus is an area that reveals deep-seated societal differences not easily susceptible to legal harmonisation. For this reason, it provides an ideal testing ground for the arguments on diversity in the internet age. By implication, this article is not concerned with the small core of child-related internet wrongdoing States across the globe agree upon (e.g. child abuse images and grooming), but looks at the much wider array of activities in relation to which diversity is great and consensus unlikely and yet 'solutions' are needed. The unlikelihood of such consensus and, therefore, of legal harmonisation means that the internet will continue to expose us to the legal systems of other societies although one may query to what extent online users in fact stray beyond their cultural/linguistic comfort zone. Yet, in any case, our physical borders no longer protect us from the 'strangeness' of the Others. Online the world converges; no matter how protective the laws of any particular State, on the internet the most permissive standards prevail. Much of the 'rogue' content online is legal or at least tolerated somewhere.

An alternative solution (other than harmonisation) to dealing with inappropriate content coming from the 'outside' is to impose our current borders onto cyberspace and create cyberspaces that mirror traditional countries. [10] Cyberborders could be drawn and are already drawn, either through the voluntary blocking actions of foreign providers or by filtering foreign content through ISPs. While the most high-profile examples of hard-core filtering are China, various countries in the Middle-East and South-East Asia, territorial segregation also routinely occurs in western democracies when content providers create country-specific sites with restricted access to users from outside that country (to avoid falling foul of foreign laws), or when ISPs and other intermediaries are ordered to block foreign infringing sites (e.g. ThePirateBay in many European countries). [11] Russia has introduced a law according to which sites that are considered harmful to children (i.e. sites featuring or soliciting child pornography, encouraging suicide or drug taking) are blacklisted and blocked via ISPs, [12] and the UK has an ISP-blocking regime in place for child pornography sites [13] and is about to introduce an opt-in version for pornography. [14] In these instances transnational communications are restricted in order to uphold local norms against otherwise infiltrating foreign content - content that does not adhere to these local norms but may well comply with its own local norms. The benefit of more solid cyberborders would be the ability to uphold local norms, the price paid is restricted transnational communications; we can no longer make use of the globality of the internet. This is far from ideal and explains why cyberborders have so far not been routinely adopted in western democracies and why legal harmonisation is presented as the ideal response to the global internet. It does away with the need to create cyberborders and retains the openness of the internet, as foreign (harmonised) content would not present a threat to local laws. Yet, harmonisation by definition irons out diversity in legal systems and here the question is not just whether this is feasible, but also whether it is desirable, given that legal rules/systems reflect long-grown values at the heart of cultural identity.

The discussion below shows, first, the very limited ambit of legal harmonisation in the online child protection context (much like in most other legal areas) despite the perceived 
urgency of many of the issues - which, in itself, is a reflection of the diversity of values on the topic. [15] The discussion then takes snapshots of where, why and how the law has previously expressly endorsed diversity as a value against 'globalisation' pressures, rather than simply treated it as a practical hurdle to harmonisation. Second, the article moves onto online child protection, with particular focus on Europe and the UK, and argues that preinternet forms of globalisation that triggered the emergence of the cultural diversity agenda, are both continued and discontinued by the full-on confrontation with multiple Otherness on the internet. While one may have expected that States would respond to this confrontation with a re-valuation of their value systems and substantive legal rules, this has not been the case. In a rather blinkered way, States have continued to insist upon their way of ordering things which, as will be seen, creates serious legitimacy concerns on a number of levels.

\section{Cultural/Legal Diversity - the New Biodiversity?}

\subsection{Legal Harmonisation and its Limited Success}

It is often assumed that the best cure for online legal ills considering their cross-border dimension is harmonisation: a global solution to a global problem. Yet, harmonisation has been slow in forthcoming in response to globalisation trends generally; similarly there has also been relatively little convergence of legal norms:

'Against all expectations that globalization of the markets and computerization of the economy will lead to a convergence of legal regimes and to a functional equivalence of legal norms in responding to their identical problems, the opposite has turned out to be the case. Against all talk of 'regulatory competition' which is supposed to wipe out institutional differences, legal regimes under advanced capitalism have not converged.' [16]

Nonetheless, in the child protection context, there have been some apparent success stories. [17] There are the Council of Europe's Cybercrime Convention (2001) [18] that deals with child pornography (Art 9), and the Convention on the Protection of Children against Sexual Exploitation and Sexual Abuse (2007), [19] the Optional Protocol to the Convention on the Rights of the Child on the Sale of Children, Child Prostitution and Child Pornography (2000), [20] and the EU Directive on Child Exploitation and Child Pornography (2011). [21] What all these instruments have in common is that their ambit is restricted to a small core of universally condemned behaviour vis-à-vis children, i.e. child abuse images and associated abuses. This makes perfect sense in light of statistics that 'reveal that at least 1 million child pornography images are currently on the internet. This figure is estimated to be increasing by 50,000 new images per annum through an underground industry that this is thought to have already generated up to 250 million Euro in revenue.' [22] No doubt, a joint effort by all States is what is needed.

However, the fact remains that these international and regional instruments do not venture into the much wider range of child protection issues, such as the exposure of children to unsavoury material (hate sites, pro-anorexic and self-harm sites, sites on drug-taking or suicide or sites with pornographic material [23]) or the sale of various items potentially unsuitable to children (alcohol or weapons or chemicals). And even in respect of the core of behaviours which these instruments do tackle, much room is left to diversity on defining issues. For example, the Cybercrime Convention allows Parties to dis-apply certain child 
pornography offences (e.g. 'possessing child pornography in a computer system') as well as variations as to what may be classified as 'child pornography' (e.g. involving 'a person appearing to be a minor'). [24] All of the instruments allow for diversity in respect of the critical question as to who is a 'child'. Under the Cybercrime Convention a minor is anyone under 18, but may also be limited to those under 16 by Party States. [25] The Convention on the Protection of Children against Sexual Exploitation and Sexual Abuse starts off decisively by defining a child as any person under the age of 18, [26] but it is left to the Party to 'decide the age below which it is prohibited to engage in sexual activities with a child.' [27] Similarly, the EU Directive which defines a child as anyone below the age of 18 , leaves it to the law of the Member States to decide the 'age of sexual consent' [28] which is then used as a building block for many of the subsequent offences. The point here is simply to show that although harmonisation has occurred, its ambit is limited, both in terms of its subject-matter and the residual discretion on key definitions left to States. As a side note, even where formal harmonisation has been achieved outside the child protection context, e.g. in Europe in respect of data protection, or across the globe in respect of copyright infringement, often the implementation of these harmonised standards at ground level creates vast divergences reflecting cultural values and thus ironically perverts the aim of harmonisation. [29]

Generally, the limits of the achieved harmonisation tend to be constructed as the limits of its success, particularly by academics. [30] This pro-harmonisation perspective is partially legitimate because, as mentioned above, harmonisation indirectly deals with foreign noncompliant online content that otherwise could only be dealt with by erecting cyberborders or, be left unregulated and thereby undermine national law spaces. Yet, harmonisation too, by definition, undermines national law spaces and cultural identity (other than perhaps the law space of the dominant power in the harmonisation process) and therefore it is as 'threatening' as its absence. This article does not investigate the reasons for the reluctance to harmonise or even the relative lack of legal convergence. Lacey, for example, has argued in the context of punishment that 'political-economic forces at the macro level are mediated not only by cultural filters, but also by economic, political and social institutions... [which] impact on the interests, incentives and indeed identities of relevant groups of social actors, which produce the significant and persistent variety which, notwithstanding globalisation, we see across systems at similar stages of capitalist development.' [31] This article merely seeks to document the significant variety in legal regimes in the child protection context and the ramifications of this in the online world. The starting point, however, is that it might be useful to move away from a perspective that extols harmonisation with a view to opening up the online governance debate to other regulatory possibilities - possibilities that are more responsive to a politically more realistic pluralism of value/legal systems. If one took as the starting point that cultural/legal diversity [32] is as valuable as biodiversity and thereby an 'end point with intrinsic value that ought to be protected' [33] or, even if not, that it is here to stay for some time to come, then harmonisation is no longer so obviously the cure for all online transnational legal ills. (Note, there is some evidence that directly links biodiversity and cultural diversity. [34])

\section{2 'Cultural Diversity' - a Response to Economic Globalisation}

At both European and international level, the value of cultural diversity emerged as a counterweight and resistance to economic integration, in Europe through the European Union and internationally through the WTO. This clash between cultural identities, on the one hand, and the economic global village, on the other hand, shows on the most basic level 
that culture and trade do not occupy two parallel universes, but are inextricably linked. Culture in a wide sense is constituted not just of folk dances and costumes, but a plethora of human activities, including long-established industries (e.g. wine in France, whaling in Japan) and culture in a narrow sense is often commodified (e.g. music, film, art) and thus also implicated by trading agreements. [35] Trade liberalisation has posed challenges for the preservation of cultural diversity through the creation of competition imposed on national industries that were previously sheltered by protectionist state policies and the subsequent rise of oligarchies of multinational corporations and their homogenising effect; [36] and, especially in the EU, also through a move towards harmonised legal standards that clear the last hurdle to uninhibited cross-border trading. [37]

In Europe increasing economic integration triggered a growing consciousness of cultural identity and the value of diversity, possibly particularly in the sphere of communication media. The push for a 'European audiovisual area' in the 1980s prompted some to foreshadow a concern that seems pertinent today:

'As an antidote to the internationalisation of programming, and as compensation for the standardisation and loss of identity that is associated with global networks, we have seen a resurgent interest in regionalism within Europe, appealing to the kind of situated meaning and emotional belonging that appear to have been eroded by the logic of globalisation.' [38]

Culture was included within the ambit of the EU through the Maastricht Treaty (1993) - not with the aim of harmonising it but preserving its diversity. Now Art 3(3) of the Treaty on the EU provides - after stating the aim of the EU being the establishment of an 'internal market' - that '[the Union] shall respect its rich cultural and linguistic diversity, and shall ensure that Europe's cultural heritage is safeguarded and enhanced.' [39] Similarly Art 167(1) of the Treaty on the Functioning of the European Union states that the 'Union shall contribute to the flowering of the cultures of the Member States, while respecting their national and regional diversity and at the same time bringing the common cultural heritage to the fore.'[40]

One concept that, at least partially, gives diversity a practical hand in the EU is the concept of subsidiarity. Subsidiarity has become a key mechanism for deliberating on regulatory competence when it is shared between the EU and Member States. [41] It requires that competence is exercised at the lowest possible level, i.e. within the EU context at local, regional or national level - unless 'the objectives of the proposed action cannot be sufficiently achieved by the Member States... but can rather, by reason of the scale or effects of the proposed action, be better achieved at Union level.'[42] With terms like 'sufficiently' and 'better', the concept has necessarily remained highly contested, with some arguing that it creates a presumption against European action, and others that it 'load[s] the dice in favour of Community action... [setting] a test which it is likely to pass.' [43] Although in the subsidiarity context we are dealing with centralisation-versus-localautonomy rather than legal-harmonisation-versus-legal-diversity, there is an overlap between these dichotomies, given that centralised law-making tends towards, and is motivated by, the simplicity and effectiveness of harmonised solutions. [44] By the same token in reverse, harmonisation is best achieved through centralised decision-making. So by preserving regional autonomy/self-determination at least in so far as it is effective, subsidiarity certainly also protect s local values and identities and implicitly diversity. [45] In the context of transnational online activity, subsidiarity is unlikely to offer any protection of peculiar national values. Typically the UK government, whilst much in favour of 
subsidiarity as a curb on centralised EU power, thought that it was 'of course true that issues which have cross-border implications will often be dealt with more effectively by EU-wide action...' [46] Subservient to the higher demand of effectiveness, subsidiarity would not come to protect legal diversity in the online environment where transnationality is invariably lurking in the background. Nonetheless, the concept is a relatively recent example of a legal pressure against harmonisation.

Similarly at international level, WTO-led trade liberalisations were promptly followed by an awakening to their consequences for cultural practices and identities:

'The emergence of 'cultural diversity' as a key concept of international political importance is related to the intensification of economic globalization during the last decades of the twentieth century. Rapid technological development has reduced the cost of transportation, offered a new means of global communication, and led to a gradual integration of national economies into borderless global economy.' [47]

Small concessions to distinct value systems were made under trade agreements in the form of the 'public morals' exception in Art XX(a) of the General Agreement on Tariffs and Trade (GATT) and Art XIV(a) of the General Agreement on Trade in Services (GATS). [48] This exception allows States to adopt and enforce trade restrictions necessary to protect public morals and has been invoked e.g. to ban the import of pornography or 'indecent' material, narcotics, games of chance, and in some Islamic countries swine products, alcohol and printed matter that contradicts Islamic teaching. [49] Significant as this exception has been, it is limited in ambit and not enough to limit the homogenising effect of economic integration. 'Cultural diversity' emerged as a WTO-counterweight most prominently in the UNESCO Convention on the Protection and Promotion of the Diversity of Cultural Expressions (2005). This Convention was specifically designed as a counterbalance to the imperative of economic integration: to reaffirm and boost the 'sovereign right of governments to formulate and implement cultural policies and to adopt measures to protect and promote the diversity of cultural expression' (Art 5). [50] Without further elaborating on the Convention and its necessarily problematic relationship with WTO agreements, [51] it is clear that, just like in the EU, 'cultural diversity' at the international level rose as a concept of resistance to economic integration. It is a value outside a purely economic frame of reference that makes everyone a consumer of no particular nationality. For corporations cultural identity is not simply irrelevant in their construction of people as consumers rather than citizens (with national boundaries being a relic of the past) but presents an obstacle to creating favourable conditions for the acceptance of a single product across a wide geographic area. 'The global corporation... looks to the nations of the world not for how they are different but how they are alike... [and] seeks constantly in every way to standardise everything into a common global mode.'[52]

\section{3 'Cultural Diversity' - within Human Rights Universalism}

A very different area, against which cultural diversity has set itself up as a counterweight and modifying force, is that of global human rights normativity. Here it redefines foundational constitutional standards (rather than foundational market norms) that embody human rights universalism giving all human beings an entitlement to the same minimum rights to allow for a life in dignity. 
How does cultural diversity interact, or in fact clash, with human rights universalism? On a most basic level, human rights law protects and celebrates minorities and pluralism through rights, such as the right to freedom of thought, conscience and religion, [53] freedom of expression [54] and the prohibition of discrimination based on 'sex, colour, language, religion, political or other opinion, national or social origin, association with a national minority, property, birth or other status.' 155$]$ These rights mean that States must be flexible enough to accommodate internally differences in value systems and practices amongst its people. Taking one step further, there has been a growing recognition that focusing only on individuals and on non-discrimination is not necessarily sufficient to preserve minority cultures. At times positive rights conferrable only on groups are needed, e.g. political representation, [56] to promote them effectively. [57] While even in this context cultural diversity is legally protected within a single State, the greater or lesser self-control of a minority group [58] (with self-determination claims presenting the final frontier to full autonomy) foreshadows parallel legal systems and divergent legal standards (legal pluralism). Implicitly it accepts that the complexities, inefficiencies and costs of parallel systems are a price worth paying to preserve cultural differences. For the purposes of this discussion, these minority rights regimes do not cater or even envisage the need for diversity claims by States themselves vis-à-vis globalisation pressures, as States are the actors assumed to be in control over such matters.

Although the very concept of human rights serves to protect minorities from the tyranny of the majority, [59] the European Court of Human Rights has at times allowed the 'cultural identity' of a State to trump that of a minority within a State. For example, it upheld Turkey's prohibition on the wearing of headscarf-hijab in universities as not inconsistent with the ECHR, on the basis that:

'It is not possible to discern throughout Europe a uniform conception of the significance of religion in society... and the meaning or impact of the public expression of a religious belief will differ according to time and context... Rules in this sphere will consequently vary from one country to another according to national traditions... Accordingly, the choice of the extent and form such regulations should take must inevitably be left up to a point to the State concerned, as it will depend on the domestic context...' [60]

This latitude given by the Court to Member States is accommodated by the concept of the 'margin of appreciation' - a concept which caters for some differences in the interpretation of the Convention by different States, i.e. a form of human rights relativism, based on the State's 'domestic context'. With certain parallels to the concept of subsidiarity, the 'margin of appreciation' thus creates room for differences in culture and in the ordering of society with something as fundamental as human rights. Given the universality of human rights it is significant that here too differences are allowed based on national traditions and identities.

The permitted diversity at the higher level (i.e. the freedom of a State to deal with the right to religion according to its culture) trumped - at least within a certain margin - a diversity claim at the lower intra-State level (i.e. the freedom of religious minorities). This shows that cultural identities can be, and often are, in competition with each other, and that the political construction of one 'culture' (possibly of necessity) entails the exclusion or inhibition of another. Along these lines it may be argued that the ECHR attitude to the 'margin of appreciation' varies depending on whether the alleged discrimination allows or suppresses challenges to what it constructs as a European culture(s): headscarves do not fit well within that construction. [61] Certainly the European interest in the preservation of 
'European' cultural diversity has, in the last decade, gone hand in hand with a perception of a threat to that heritage from the outside, in particular from the Muslim world: 'a particular narrative has begun to take hold across Europe and the U.S. in more recent years - that of the apparent failure of state multiculturalism. Those on the far-right of the political spectrum... have long contended that multiculturalist policies are necessarily divisive, promoting 'obscene level(s) of injustice towards the indigenous population.' However, this debate has increasingly entered the mainstream...' [62] When the endorsement of 'European' diversity has gone hand in hand with the rejection of non-European traditions that appear to be threatening so-called European values, premised on the 'existence of pure, internally homogenous and authentic cultures' [63], it becomes clear that diversity/identity claims are also potentially highly problematic and may be used as an exclusionary, rather than liberal device.

This cursory examination of cultural diversity shows that it has cropped up in various legal and political contexts under numerous labels and concepts (e.g. pluralism, multiculturalism, heterogeneity, self-determination, nationalism, [64] cultural relativism, subsidiarity, margin of appreciation) as an antidote to globalisation which also has come in a multitude of disguises (e.g. integration, assimilation, harmonisation, homogeneity, cohesion, unity, standardisation, universalism). In fact, the emergence of cultural diversity as an important political value and as legal concepts of resistance tends to be tied to different forms of globalisation and their homogenising effects. It has arisen in response to the reductionist economic perspective of trade liberalisation regimes that only recognise economic actors in competitive markets and are insensitive to cultural practices and to citizen-oriented public goods; and in response to the universal human rights paradigm that is reductionist in its focus on the vulnerabilities and needs of human individuals and largely insensitive to the histories and sensitivities of groups and their collective value systems. In these cases, cultural diversity in various disguises has forged necessarily uneasy inroads into these global or regional regimes.

\section{Cultural/Legal Diversity in Cyberspace: Child Protection}

The internet follows in the footsteps of economic globalisation in terms of having increased our interactions with the outside world, both on a qualitative and quantitative level. These interactions certainly have some homogenising effect: everyone regardless of location is, at least in principle, exposed to the same cyberspace - even if our distinct physical-cultural context steers us into different online directions as well as influences the way we engage with, and construct, the same online world. Furthermore this space is also increasingly dominated by a few transnational corporations, mainly from the US, e.g. Google, Facebook, eBay, Amazon, Apple (much like previous media empires such as Warner Brothers or News Corp) which in spite of their global unifying presence steer us towards familiar cultural grounds.

The online confrontation with globality breaks with tradition in two significant ways. First, it gives ordinary users the potential to engage in mass communications and thereby attract legal significance, [65] no longer requiring mediating corporations which in the past have acted as useful territorial anchors and regulatory gatekeepers. Traditional diversitypreserving concepts, such as subsidiarity, would not function effectively in cyberspace, as they are made for a world where activity has varying territorial impacts which 'signal' the 
appropriate regulatory level: local, national or European. On the internet, while much online activity is clearly more 'located' in some places than others (e.g. website of Aberystwyth University sports club 'belongs' more to the UK than China), in principle unless the activity is specifically restricted to a certain group/territory, there is no local and everything is international. Especially for purposes of criminal law, the possibility of illegal foreign sites being accessible is sufficient to raise its head.

Second and related, unlike the economic integration agenda promoted by industrialised States on behalf of their corporate interests, the internet presents a form of bottom-up globalisation, i.e. through technological advances as endorsed and adopted by society and commercial interests and consumers. [66] Governments (with the exception perhaps of the US government) have had relatively little input in the emergence of the online happening. They witnessed it as bystanders, but have now been invited to the party by commercial actors eager to see their property rights protected [67] and some civil society sections keen to have their moral mores upheld. This bottom-up nature of the online globalisation explains why 'cultural diversity' as a predominantly popular concept of resistance to topdown globalisation cannot easily be positioned in the online environment which emerged precisely because of its popular endorsement. In addition, the protection of 'cultural identity' through the State, as reflected in legal norms and standards, is also hampered by the popular nature of this globalisation which has had fundamental consequences for the internet's regulability. On the one hand, governments have prima facie not been normative authorities within the new space; they are new-comers and as such they have had to abide, at least to an extent, by the space's existing shape, culture and normativity, one of which is its 'borderlessness' (i.e. the relative lack of gatekeepers). On the other hand, the noninvolvement of governments in the creation of the internet also means that a regulatory agenda was not built into its architecture, and indeed quite the reverse, considering its decentralisation. It is only now that new powerful regulatory allies and options are starting to emerge within this seemingly anti-regulatory architecture (i.e. the most obvious allies are intermediaries such as IPSs and search engines, and potent regulatory options are code and surveillance). All in all, it has been difficult for States to reclaim regulatory ground lost in the first two decades of the internet.

In terms of the internet's transnationality, this explains why cyberborders, mirroring national borders, have so far been limited - despite their necessity for upholding local normativity. Western States cannot hermetically seal their cyberborders and 'protect' their populace from foreign online content reflecting foreign value and legal systems, even if they wanted to. This 'means that those we consider as Other or alien - the 'new barbarians' [are]... in our midst' 68$]$ - and not in small numbers and from all directions. On social networking sites, for example, these legal Others (i.e. people residing in other States) are virtually as present as if they lived amongst us - but, of course, they do not, and, for most intents and purposes, they are also outside the enforcement reach of any State but their own. [69] What challenges have these online legal Others presented to States and how have dealt with them?

\subsection{Diversity in 'Agency' Standards - Children as Perpetrators}

Perhaps a society's attitude to children is best judged in circumstances when it is most difficult to side with them. When children are the perpetrators, they do not conform to the idealised, romantic image of the pure, innocent, weak and sweet [70] and it is in these situations that huge societal differences in child protection issues emerge. And given the 
popularity of the internet amongst children, their activities have not infrequently brought them into contact with criminal justice systems, e.g. for illegal file-sharing, cyber-bullying, hacking, [71] sexting and the distribution of indecent images on social networking sites. [72] As the internet magnifies previously relatively innocuous behaviour, it might in fact attract more child criminality. 'Children's malicious comments which were traditionally scrawled on the bathroom wall are now being transferred online to social networking sites...' [73] While most of these offending activities are formally transnational (in so far as the relevant communications could be accessed elsewhere but are in fact not), some are deeply transnational in that they cause damage to institutions and people in other countries and thus invoke foreign interests which may seek penalties, injunctions and reparations (e.g. file-sharing or hacking).

What are the attitudes of European States to child criminal offenders? They differ enormously as, for example, reflected in the variations on the age of criminal responsibility: 7 in Switzerland, 10 in England, Wales and Northern Ireland, 12 in Scotland, [74] 13 in France, 14 in Germany, 15 in Scandinavia, 16 in Spain and Poland and 18 in Belgium and Luxemburg. [75] These variations exist despite the fact that all these States share significant value systems, including a Judeo-Christian tradition, a commitment to reason and the 'scientific method' dating back to the age of Enlightenment, an endorsement of democratic governance, human rights and the welfare state. The breadth of these variations extends far beyond the statute books into societal attitudes to child criminality, as illustrated by the different legal and societal treatment of child killers in Norway and Britain in recent years:

'Just after James Bulger was murdered there was a case in Norway with almost eerie similarities: the two killers were children; there was that edge of cruelty about the way they were killed; and again the victim was a younger child - in this case a little girl. Yet the reaction of the community and the handling of her young killers marked an almost total contrast to that of the Bulger case...the way in which Norway dealt with the murder of Silje was in stark contrast to that of James Bulger's... In Norway, no children under 15 are prosecuted and Silje's killers were back at kindergarten within a week. The local community were encouraged to air their views and brought together to grieve openly. A team of counsellors was set up to work with the children in school. The strategy worked and, amazingly, there were no reprisals against either of the boys or their families. They were able to carry on living on the local housing estate. The police, the local community and even Silje's mother were united in believing that they shouldn't be punished.' [76]

While in Britain 'some 'tabloid newspaper's compared the [James Bulger] killers Robert Thompson and Jon Venables to Myra Hindley and Saddam Hussein', [77] the Norwegian media coverage was composed; it did not disclose the names of the offenders as it was perceived important that the boys had a chance to recover and the chance of a normal life. [78] The differences in the societal responses provide the wider context for the legal positions and shed some light on why England's age of criminal responsibility is 10 and Norway's 15. Importantly too, these attitudes have far reaching historical roots:

'the Anglo Saxons also had debates that resonate to this day about the age at which a child could be said to be responsible for her or his acts, perhaps by implication the age at which childhood ended. Ine of Wessex thought that 'A ten-year old child may be regarded as an accessory to theft.' In the tenth century Aethelstan, king of England (893/4-939)... declares that he, and those with whom he has spoken, think that no one should be executed who is 
under fifteen years, unless he tries to defend himself, or tries to run away and refuses to give himself up.' [79]

Many centuries and much scientific progress later, including the birth of psychology, paediatrics and extensive research into child development, Britain still has the same age of criminal responsibility as the Anglo-Saxons had; only the sentences have changed. [80] These national variations are not problematic per se; they do, however, undermine claims of the neutral and apolitical nature of legal standards upon which most liberal democracies insist. By way of example, English criminal law has ostensibly moved away from 'an overt evaluation (malice) to a factual, psychological state (intention), hence (apparently) distancing controversial moral and political judgments from the courtroom', [81] but more on legitimacy concerns below. For the moment, while it may be possible to argue that this age or that age is more in tune with current knowledge on child development, what is certain is that childhood is a fluid concept that defies hard and fast definition. Even within a single jurisdiction there is little consensus on its boundaries. [82] By the same token, the European variety on the age of criminal responsibility is matched by an equal variety on the age of sexual consent, with the youngest age being in Spain (13) and the oldest in Turkey and Malta (18). [83] This has serious implications for numerous internet-related offences e.g. child abuse, grooming, offering pornography to the underaged - both for the child and the would-be offender. [84] More generally, however, it shows that childhood has contracting and expanding boundaries depending on the legal subject-matter invoked and the socio-cultural context.

Prior to the internet these different sets of national rules could co-exist relatively undisturbed in parallel because direct transnational activity was rare and, as noted above, generally mediated through large corporations that were regulated so as to reflect local normativity, thus avoiding conflicts between different legal regimes. The internet makes such conflicts more common and overt. This has consequences on a practical and legitimacy level. First, on a pure practical level, one consequence of these differences in legal standards is that mutual cooperation is much less forthcoming - across the wide spectrum of criminal justice. In Europe, despite advances made in the development of European criminal law, Art 3(3) of the Council Framework Decision on the European Arrest Warrant (2002)[85] which largely discards the double criminality rule typical for extradition agreements, specifically excludes cooperation where the age of criminal responsibility varies:

'The judicial authority of the Member State of execution... shall refuse to execute the European arrest warrant... if the person who is the subject of the European arrest warrant may not, owing to his age, be held criminally responsible for the acts on which the arrest warrant is based under the law of the executing State.'

If a teenager of 14 in Finland hacks into the computers of British intelligence services or runs an illegal file-sharing site that infringes British copyright, or distributes via a social networking site explicit sexual images of his 13-year-old girlfriend, Finish authorities would neither bring a prosecution against the teenager nor extradite him to Britain where prosecutions could take place. Outside the EU context, the same refusal to cooperate would flow from the double criminality requirement in extradition agreements. Thus a State has no redress against a foreign child offender even where a local child could be prosecuted. (Note, in contrast to the atypical approach, discussed below, i.e. film classifications, States have generally extended their laws to cyberspace and treated online activity exactly the 
same as offline activity.) The State's only option in respect of the foreign offending would be to block the material at its cyberborders/ISPs, but clearly this does not quite do justice in the matter.

Second, the online confrontation with legal diversity presents serious challenges to the legitimation of national law, especially clearly coercive criminal law, which legitimatises itself, on a substantive level, by 'appealing to the normative, purportedly 'objective' status of the standard which it applies... [and on a formal/procedural level] by appealing to the detached and even-handed application of its standards to all who come before it.' [86] In respect of the latter, the fact that a foreign child can do something online with impunity that a local child cannot, undermines the legitimacy of the relevant rule and, by implication, of the rule maker. Every child knows it is only fair that the same rule should apply to the same type of conduct by the same type of actor in the same environment. Formal justice is missing. On the substantive justice front, the online confrontation with the distorting mirror images of foreign value systems challenges the 'objectivity' of our legal standards and the values that underlie them, especially when these distorting images come from relatively 'respectable' Others, such as our European neighbours. No longer are our legal regimes selfevidently correct and this in turn challenges 'the power of law [that] depends on the capacity of legal discourse to construct itself as generating 'truths' which are impervious to critical scrutiny from other perspectives.' [87] This is particularly unsettling in respect of an issue as morally sensitive as child offending.

So the pluralism/diversity with which the internet confronts us presents a frontal attack - on a formal and substantive justice level - on the legitimacy of national law spaces, and the values they represent. That confrontation is not unprecedented in kind, but it is in scale. For States the situation is precarious: as late-comers to the internet they lack the legitimacy to impose more solid cyberborders and then suffer further legitimacy losses because of the double-standards that arise because of the lack of these borders.

\subsection{Diversity in 'Harm' - Children as Victims}

In the case of children as perpetrators, the uncooperativeness of States in criminal justice matters tends to produce ineffectiveness of law enforcement and thus arguably leniency and protectiveness for the offending child. [88] That same ineffectiveness of law enforcement is more problematic where children are the victims of online criminality - with more pressure on governments to respond, rather than remain bystanders.

\section{Diversity of 'Harm' - Socio-Cultural and Legal Constructions}

When considering children as victims of 'harmful' online activity, the confrontation with diversity arises because of a variety of conceptions of harm. Outside a core of misbehaviours (see above discussion on harmonisation) - what is or is not harmful has been hotly disputed across cultures and across time, much like the boundaries of childhood. In England the harm principle has been of constitutional concern, at least since John Stuart Mill, who thought of 'harm to others' as the legitimising principle of governmental interference with individual liberty, [89] but has also raised academic questions about the sociocultural and legal construction of harm. [90] What is certain is that 'harm' is 'neither fixed nor analytically robust' [91] - a fact which is not easily squared with the presentation of criminal law as neutral and objective. 
In his very successful book Psychological Care of Infant and Child (1928) John B Watson, an influential American psychologist in the emerging field of child development, wrote the following with some confidence:

'The sensible way to bring up children is to treat them as young adults. Dress them, bath them with care and circumspection. Let your behavior always be objective and kindly firm. Never hug and kiss them. Never let them sit in your lap. If you must, kiss them once on the forehead when they say goodnight. Shake hands with them in the morning. Give them a pat on the head when they make a good job of a difficult task... Put the child out in the back yard a large part of the time... Do this from the time that it is born... Let it learn to overcome difficulties almost from the moment of birth... away from your watchful eye. If your heart is too tender, and you must watch the child, make yourself a peephole, so that you can see without being seen, or use a periscope.' [92]

Those views are no longer en vogue, but this does not mean that we have come any closer to knowing what is 'harmful' to children; nor, of course, could we. The indeterminacy of 'harm' and its societal construction shines through the findings of Livingstone and her team in her EU Kids Online survey (2011) include the following:

'Children encounter pornography online and offline - 14 per cent of 9-16 year olds have seen sexual images online, and 4 per cent (about 25 per cent of those who had seen sexual images online) were upset by this; 23 per cent have seen sexual images altogether (including on websites, but also television or videos/DVDs...magazine or books...).' [93]

This puts a question mark on quite how problematic online pornography is in comparison with other offline sources of sexual images. Also a background assumption of the survey appears to have been that there is some equation between 'being upset' and 'harm' [94] and yet, children may well be upset when their parents send them to school. The search for 'harm' becomes a self-fulfilling prophecy in a society that has decided that something must be harmful. The UK Government commissioned Byron Report (2008) found that 'there is a small but accumulating body of evidence showing a link between exposure to sexually explicit material and negative beliefs and attitudes, although this research cannot decipher the direction of causality.' [95] Assuming that the important issue of causality could be solved, we may want to question as to who decides that a belief and attitude was 'negative'? Also as 'negative' could be replaced with 'harmful', the evidence in question simply appears to assert that children's exposure to sexual images is harmful, which in turn 'proves' that it is harmful. In light of the socio-political dimension of 'harm' States are bound to, and in fact translate ambiguous facts into very different conclusions on the appropriate regulatory regimes. This is borne out by the different ratings given by States to the same films and with the same objective of protecting children (discussed further below): 'Pulp Fiction, The Exorcist, Hannibal, Gangs of New York and Secretary were all rated 18 in Britain yet received a more lenient 12 rating in France.' [96] In short, there is no fact-regulatorysolution determinism generally or in the online child protection context in particular. This, one might think, would dispose States towards recognising the non-conclusiveness of their solutions to indeterminate problems and thus to exploring common standards. Yet, the socio-cultural dimension of 'harm' coupled with the regulatory discourse of objectiveness adds a conclusiveness that makes political dialogue between States on those issues close to impossible, as implicit in a common approach would be the non-recognition of 'harm' according to national consciousness. This has remained unchanged, even as States have, 
online, been squarely confronted with foreign 'barbarians' who provide a constant reminder of cultural and legal Otherness.

\section{Resistance to Harmonisation in Film and Games Rating Regimes}

The purpose of film classification is to protect children from harmful content. [97] This is one area that has been severely shaken by the internet because of the divergence of regional and international standards. [98] In respect of US and the UK, two culturally relatively close States, it has been said: 'the main difference between the BBFC and US censors [MPAA] is that the US [board] is more squeamish about sex, but more tolerant towards stronger violence.' [99] Film classification appears to present the epitome of cultural sensitivity combined with the morally delicate issue of child protection:

'film classifications can often deviate so much from country to country that it seems that such decisions are based less on general, scientifically founded principles than on certain concepts about childhood and adolescence. How else might such differences be explained and justified, when each and every country claims to be pursuing the same objective...? Upon closer observation... it is clear that there is no uniform concept in this field... Instead, it depends very much on the individual country and its specific culture.' [100]

When in 2004 the EU proposed to examine the feasibility of a Europe-wide rating system for films, the then director of the British Board of Film Classification (BBFC), Robin Duval, described the idea as 'an impracticable chimera' pointing to the vast differences in classifications for films in different European States. [101] States have resolutely hung onto their right to protect the moral fabric of their societies according to their peculiar visions, despite a generation of connected children growing up with YouTube, streamed films and series and Massively Multiplayer Online Games.

One notable recent exception to this unwillingness to harmonise is The Pan-European Game Information (PEGI) which provides a European-wide rating system for video games. Importantly, this was not a government initiative, but set up in 2003 by industry actors, including major console manufacturers, such as Sony, Microsoft and Nintendo and European developers and publishers of interactive games, [102] with a nod from the European Commission being supportive of this harmonisation initiative. [103] Initially voluntary, PEGI has since been brought onto a statutory footing in a third of the States that 'use' it, one of which is the UK where it is enforced by the Video Standards Council. [104] The common standards which European governments were so unwilling to adopt for films, commercial stakeholders sneaked upon them - treading softly with a self-regulatory version - for video games. Are these two rating regimes reconcilable: do the harmonised video games ratings not undermine the value systems reflected in the country-specific film ratings? Also, as noted above, for companies, having these common standards facilitates the selling of the same product to an ever expanding market: the 'global corporation... looks to the nations of the world not for how they are different but how they are alike... [and] seeks to constantly in every way to standardise everything into a common global mode.' [105] Quite regardless of whether the harmonised outcome is or is not desirable, should commercial efficiency be the consideration that settles the issue of cultural identity? Should it be corporations that make those decisions, rather than democratically accountable governments and indirectly the public at large (i.e. BBFC's rating decisions are based on the British public's sensitivities [106])? 


\section{The Offline - Online Duality in the Film and Games Ratings Regulation}

In any event, the ambit of the Pan-European video games rating regime is limited given the online universe, first, because it only extends to video games sold in Europe and thus, with minor exceptions, discounts non-European providers easily accessible online. Second and related, national enforcement actions have stayed clear of the online games scene altogether. [107] For example, the new UK enforcement regime of the compulsory rating and labelling requirements for video games applies to the 'supply of... video games in the form of the physical product (such as discs, magnetic tape and other physical storage devices)' $[108]$ at the pain of heavy fines and up to two years imprisonments, [109] but not to online games. Indeed, if anything, in the UK the regulation of the offline video game industry has been tightened, as if a more rigorous regulation of offline games could somehow compensate for the loss of control over the online world. [110] The same schizophrenic off/on-line division also applies to films. [111] BBFC ratings are strictly enforced for cinemas and shops, but only extended on a voluntary basis to the world of 'digital downloads from iTunes, or streaming from Netflix or Amazon's LoveFilm [that] are rapidly usurping "packaged media".' [112]

The reason for this split ordering is, of course, not a political unwillingness to deal with online films or video games, but the inability to do so effectively - without erecting solid cyberborders. The BBFC simply has no avenues for enforcing rating requirements against foreign online games, films and video clips, such as YouTube videos and the like. Prior to the internet, not only did all films available in Britain, bar a few exceptions, have to be classified, but that classification went hand in hand with its enforcement through local suppliers of films, i.e. sale, hire and cinemas. Regardless of parental choices, a child could not see an 18-rated film in a cinema or buy or hire it. [113] While parents could override that State protection and value system in the privacy of their home, in the public sphere it was the State that dominated. That boundary between the private and public spheres has become more blurred with and on the internet (e.g. internet access in public places on mobile phones or social networking sites) with the paradoxical result that regulatory inferences are seemingly both greater in the private sphere and less in the public one.

In the film context, State regulation has been abandoned in favour of parental control, supported by a multi-layered network of 'voluntary' actions by commercial stakeholders for online films and videos. [114] For example, the BBFC has issued more than 200,000 voluntary classification certificates to online-only video content, pushed by an increasing number of digital platforms that seek to attract the approval of parents through ageappropriate labelling. [115] Interest in online classification has been rising sharply, [116] possibly reflecting - as some have argued - 'a political shift taking place in relation to online content... [driven by] both politicians and the public.' [117] Whatever that surge in interest in online classification may show about the changing popular attitude to the internet, what is certain is that the classifications are voluntary and this means effectively the State has withdrawn from this regulatory agenda as a significant and influential actor. The entire rhetoric about online child protection, much of it coming from industry, is infused with terms such as 'self-regulation', 'empowering parents', 'tools for parental control', 'education', 'awareness-raising' and similar concepts, indicating the shifting borders of control. [118] On the internet, parents are left alone to manage their children and children are left alone with their 'managing' parents and at times left alone altogether (which may not be a bad thing): 
'more than a quarter of 11-15 year olds (27\%) say their parents don't know what films they are watching online.' [119]

This withdrawal of the State as a systematic enforcer of moral norms for children in this particular context, in favour of parental supervision, occurs reluctantly - considering the regulatory ambitions of Western States vis-à-vis most facets of modern life. [120] More specifically, the UK's continued insistence on control over what children can and cannot watch offline (much like other European States) testifies to a very strong interest in such moral/cultural ordering:

'State governments have their own separate interests regarding the state's children, and those interests do not necessarily coincide with the interests of a child's parents. Small-scale non-state societies also have their own interests, but a state society's interests are more explicit, administered by more centralized top-down leadership, and backed up by welldefined enforcing powers. All states want children who, as adults, will become useful and obedient citizens, soldiers, and workers. States tend to object to having their future citizens killed at birth, or permitted to become burned by fires. States also tend to have views about the education of their future citizens, and about their citizen's sexual conduct.' [121]

It is beyond the scope of this paper to speculate how this withdrawal of the State from the moral-and-cultural-tone-setting agenda in this area might, long-term, affect children and the social fabric of society more generally - whether children will become less obedient adults; whether society will be more fractured or more creative and perhaps more tolerant; or whether parental dominance might bring social mobility to a full stop? And how will it affect cultural identity?

\subsection{The Limits of National Normativity and a Choice of Legitimacy Dilemmas}

This withdrawal of the State from the online regulatory agenda in respect of film and games ratings is atypical. In general, as is prima facie the case for child offenders, States have extended their criminal and regulatory laws to the online world - including to sites and online activities originating from abroad. [122] However such foreign activity is, in all but exceptional circumstances (e.g. the foreign perpetrator enters the country), outside their enforcement jurisdiction even if, as is usually the case, States have in principle a right to regulate it based on its effects on their territory. [123] So when States do not withdraw from the regulatory agenda, in practical terms they still cannot keep the barbarians out (unless they resort to blocking at their cyberborders, which so far has not been taken up as a mainstream solution). This inevitable loss of control appears to be accepted in the ratings scenario; yet it is accompanied by a renewed vigour in enforcing their national legal standards in the offline world.

The regulatory approaches to transnational online activity, as illustrated in the child protection context, show that States have a choice as to where to draw the boundary between their orderly, culturally distinct spaces and the barbaric world apart, but that either option presents serious challenges to the legitimacy of national law. and that the final outcomes are not dissimilar. When they take the standard approach, as they do in respect of online child offending, they judge online behaviour by the same legal standards as offline offending. But as this can only be enforced again local wrongdoers, such regime does still 
not deal with the legal Other, but creates small domestic pockets of local normativity online. As argued above, this creates a legitimacy problem in terms of not applying the same legal standards to the same conduct, depending on whether the provider is foreign or local. So consistency of treatment, or formal justice, is absent.

Alternatively, as in respect of film and games rating, for example, the UK - via its legislative regime - decided not to extend its rating regime to online-only films and games. So here the boundary between the orderly national space and the barbaric world apart is drawn between the offline and online world. This approach also creates a legitimacy problem in so far as it distinguishes between physical and purely online films and games. However, arguably this latter inconsistency is less blatant because it is more in tune with the perception and construction of the online world as being a distinct space and one that is apart from the 'real' world: if you go online, you are entering a different space that is governed by different standards - surfer beware. Conversely the offline world continues to be the 'safe haven' as we know it, where the State takes an active interest in the moral wellbeing of its subjects, especially its children, and its collective cultural sensitivities.

However, this duality becomes less convincing the more the online world creeps into every nook and cranny of our offline existences. [124]

\section{Conclusion}

The internet has put regulators in an awkward position. On the one hand, they are expected to discharge their popular mandate to protect their population from the online barbarian, the Others, whose 'harmful' activities challenge cultural sensitivities and contravene local laws. On the other hand, that mandate can only be discharged by closing cyberborders, but that too offends sensitivities - this time the 'openness' standard cultivated by the online community. Harmonisation does not provide a solution to this conundrum either, precisely because it would require each party to accept and even adopt barbaric standards, or at least a compromise thereof.

The effect of this regulatory stalemate is a deeply fractured or fragmented law space, where traditional legal norms regulate the traditional offline world as if nothing had changed, while on the internet those norms make only the slightest indent in the domestic online space. Indeed there are some hints of a greater urgency for the application of the traditional legal norms to the traditional world; paradoxically the rating regimes for films and games in the offline world has seen a tightening of the existing standards - seemingly in defiance of the frontal online attack on those standards from the online Other. In some ways contrary to expectations, the online confrontation with diversity has provoked a stronger, rather than a lesser, insistence on distinct cultural/legal values, even if that insistence can only be realised for the offline world. The position of States within the international (online) community bears some resemblance to that of a minority within another dominant culture, where the minority may adhere to its standards, values, traditions and rituals within the private world of its community, but is much less and only uncomfortably able to do so within the public world of the dominant culture. How minorities respond to that threat coming from the public sphere may give us some clues as to how States will long-term respond to the internet. However importantly, the co-existence of this private world of distinctness and the public world of the Other is clearly possible. 
Morley and Robins in their book Spaces of Identity (1995) contemplated the effect of preinternet global electronic media on cultural landscapes. Whilst acknowledging the 'sheer difficulty of living with difference', [125] they also reflected on historic precedents for large pluralist societies, such as the transnational empires of the Habsburg and the Ottomans:

'the identity of imperial populations was rich... because of the complex circulations and permutations of ethnic, religious and linguistic groups, across large geographical regions of the empire. ... you could be Orthodox amongst Catholics and Muslims and Jews of all variety. Not that it was idyllic or perfect... but at least, where it prevailed, difference was never experiences as a scandal or as a defect of identity... Pluralisms and complexity was a resource and a source of enrichment.' [126]

If we think of the internet as a large pluralist society, that defies the strictures of single sets of normativity, the cultural diversity played out on it will, no doubt, remain challenging (because difference is difficult) but at the same time it might also be accepted and celebrated as a source of enrichment.

[1] Aberystwyth University, utakohl@ hotmail.com. The title 'Barbarians in our Midst' is borrowed from Morley and Robins' book, see below n 5, 25. A version of this paper was presented at a Cambridge University workshop on 'Media Governance or Media Freedom' in the Centre for Research in the Arts, Social Sciences and Humanities (30 September 2013). I am grateful to Jan Oster, Diane Rowland and Ann Sherlock for comments on a previous draft.

[2] Jared Diamond, The World Until Yesterday (Allen Lane, 2012).

[3] Ibid 196, although he also notes 'how much freedom children enjoy seems to depend partly on how dangerous the environment is, or is perceived to be' (198).

\section{[4] Ibid 197.}

[5] For an excellent treatment of the subject pre-internet, see David Morley, Kevin Robins, Spaces of Identity - Global Media, Electronic Landscapes and Cultural Boundaries (Routledge, 1995).

[6] For an overview of some of the ideas and applications, see Jean-Francois Staszak, 'Other/Otherness' in International Encyclopaedia of Human Geography (Elsevier, 2008)

[7] Emmanuel Lévinas, Le Temps et l'Autre (1948, reprinted Presses Universitaires de France, 2011)

[8] Simone de Beauvoir, The Second Sex (1949, translated by HM Parshley, New York: Vintage Books, 1974), xix, referring also to Claude Lévi-Strauss, Les Structures élémentaires de la parenté (1949) 
[9] This is not to deny the existence of significant moral/political Others within the boundaries of a State.

[10] This is the position implicitly adopted by all those who argue that competence rules under private international law or public international law can resolve the tensions between the internet and national law. These rules pre-suppose the continued existence of different substantive laws and ultimately can only be enforced and retained through the creation of cyberborders. On the options, see Uta Kohl, Jurisdiction and the Internet: Regulatory Competence over Online Activity (Cambridge: CUP, 2007) Chapter 7.

[11] Ronald Deibert, John Palfrey, Rafal Rhozinski, Jonathan Zittrain (eds), Access Contested (, MIT Press, 2011); see also the OpenNet Initiative at https://opennet.net/. See also OSCE, Freedom of Expression on the Internet (15 December 2011) which documents the wide variety of online censorship in Members States.

[12] Roy Greenslade, 'Russia's secret internet blacklist' (6 November 2012) The Guardian, http://www.theguardian.com/media/greenslade/2012/nov/06/press-freedom-russia

[13] In the UK, the Internet Watch Foundation (https://www.iwf.org.uk/) provides a hotline for reporting child pornography hosted anywhere and criminally obscene adult content hosted in the UK and those sites are reported to the police and removed at its source or, if outside the UK, blocked via ISPs (blacklist).

[14] BBC, 'Online Pornography to be blocked by default, PM announces' (22 July 2013) BBC News http://www.bbc.co.uk/news/uk-23401076

[15] Similarly, the many extraterritorial jurisdictional claims made by States over foreign online activity shows their unwillingness to not let go of their 'distinct' law space. See Kohl, above $n$, Chapter 4.

[16] Guenther Teubner, 'Legal irritants: how unifying law ends up in new divergences' in Peter A Hall and David Soskice (eds) Varieties of Capitalism: The Institutional Foundation of Comparative Advantage (OUP, 2001) 433.

[17] Arguably, the Conventions in question came about so relatively quickly because they deal with issues on which all parties had already substantially common standards.

[18] Budapest, 23 November 2001.

[19] Lanzarote, 25 October 2007.

[20] UN Doc.A/RES/54/263 of 25 May 2000.

[21] 2011/92/EU.

[22] European Commission, Global Alliance to fight Child Sexual Abuse Online (5 December 2012) http://ec.europa.eu/unitedkingdom/press/frontpage/2012/12_135_en.htm .

[23] Sonia Livingstone, Leslie Haddon, Anke Gorzig, Kjartan Olafsson, EU Kids Online II - Final Report (September 2011) 
http://www.lse.ac.uk/media@1se/research/EUKidsOnline/EU\%20Kids\%20II\%20(200911)/EUKidsOnlineIIReports/Final\%20report.pdf 28f; Lorraine McDermott, 'Legal Issues associated with Minors and their Use of Social Networking Sites' (2012) 17(1)

Communications Law 19, $19 \mathrm{f}$ (on the application of defamation law and privacy protection to children's online activities).

[24] Article 9(4): 'Each Party may reserve the right not to apply, in whole or in part, paragraphs 1, sub-paragraphs d. and e., and 2, sub-paragraphs b. and c.'

[25] Article 9(3).

[26] Article 3.

[27] Article 18(2). See also Explanatory Report, para 128: 'Paragraph 2 reinforces for the purpose of legal certainty the requirement for all Parties to the Convention to define the age below which it is prohibited to engage in sexual activities with a child. The negotiators considered the possibility of harmonising criminal law in this area by establishing a legal age for sexual relations in the Convention, but as this age varies greatly in member States of the Council of Europe (from age 13 to 17)...'

[28] Article 2(a) and (b) respectively.

[29] In relation to data protection in the EU, see European Commission, Commission Staff Working Paper, Impact Assessment of the General Data Protection Regulation and the Directive on Data Protection in Law-Enforcement, (Brussels, 25 January 2012) SEC(2012) 72 final, Annex 2 'Evaluation of the Implementation of the Data Protection Directive'.

[30] See, for example, Russell L Weaver, 'The Internet, Free Speech and Criminal Law: Is it Time for a New International Treaty on the Internet?' (2011-12) 44 Texas Technology Law Review 197; or for an earlier example, see Alexander Shytov, 'Indecency on the Internet and International Law' (2005) 13 International Journal of Law and Information Technology 260.

[31] Nicola Lacey, 'Why Globalisation Doesn't Spell Convergence: Models of Institutional Variation and the Comparative Political Economy of Punishment', in Adam Crawford (ed), International and Comparative Criminal Justice and Urban Governance, (CUP, 2011) 214, 217. See also Nicola Lacey, The Prisoners' Dilemma: Political Economy and Punishment in Contemporary Democracies (CUP, 2008)

[32] For the sake of simplicity the discussion below refers to cultural diversity, rather than cultural/legal diversity, but the assumption is that cultural diversity is almost invariably reflected in distinct legal rules and frameworks, as is in fact illustrated below.

[33] Reed F Noss, 'Indicators for Monitoring Biodiversity: a Hierarchical Approach' (1990) 4(4) Conservation Biology 355, 356.

[34] John Vidal, 'As forests are cleared and species vanish, there's one other loss: a world of languages' (7 June 2014) The Guardian http://www.theguardian.com/environment/2014/jun/08/why-we-are-losing-a-world-oflanguages which notes: 'Researchers have established a correlation between changes in 
local environments - including the extinction of species - and the disappearance of languages spoken by communities who had inhabited them' and expressly refers to 'cultural biodiversity'.

[35] Fiona Smith, 'The Limitations of a Legal Approach to the Regulation of Cultural Diversity in the WTO: the Problem of International Agricultural Trade' (2008) 3 Asian Journal of WTO \& International Health Law and Policy 51.

[36] Morley, above n 4, 17ff.

[37] Harmonisation of laws is not necessary to creating an open market but ultimately a diversity of legal standards gives manufacturers of products made under the least stringent legal requirements a competitive advantage. Thus an open market creates incentives for States to create a playing field for the economic actors within it.

[38] Morley, above n 4, 17.

[39] See also Art 6 TEU.

[40] See also Art 22 of the Charter of Fundamental Rights of the European Union (2000/C 364/01).

[41] Article 5 TEU.

[42] Article 5(3) TEU [emphasis added].

[43] UK Parliament, House of Lords Select Committee on European Union, European Union - Fourteenth Report (2005), http://www.publications.parliament.uk/pa/ld200405/ldselect/ldeucom/101/10102.htm , Chapter 2, para 70 (Professor Wyatt) .

[44] An exception here would be legal instruments on private international law and on competence questions in the public/criminal context, as in both cases the harmonised rules are designed to retain different substantive standards are preserved.

[45] George A Bermann, 'Taking Subsidiarity Seriously: Federalism in the European Community and the United States' (1994) 94(2) Columbia Law Review 331.

[46] Above n 42, para 71 [emphasis added].

[47] Christoph Beat Graber, 'The New UNESCO Convention on Cultural Diversity: A Counterbalance to the WTO?' (2006) 9 Journal of International Economic Law 553, 553f.

[48] Mark Wu, 'Free Trade and the Protection of Public Morals: An Analysis of the Newly Emerging Public Morals Clause Doctrine' (2008) 33 Yale Journal of International Law 215, where the author discussed the history of the exception and the only 'judicial' decision on it, i.e. the decision by the WTO panel in US - Measures Affecting the Cross-Border Supply of Gambling and Betting Services (Appellate Body Report, 7 April 2007, WT/DS285/AB/R). 
Note, there is also the 'protection of national treasures of artistic, historic or archaeological value' exception in $\operatorname{ArtXX(f)~of~GATT.~}$

[49] Wu ibid, 223, 250ff.

[50] Wu, ibid 558f.

[51] Anke Dahrendorf, 'Trade meets Culture - The Legal Relationship between WTO rules and the UNESCO Convention on the Protection and Promotion of the Diversity of Cultural Expression' (2006) 11 Maastricht Working Papers, http://arno.unimaas.nl/show.cgi?fid=6854; Jan Wouters, Bart De Meester, 'The UNESCO Convention on Cultural Diversity and WTO Law: a Case Study in Fragmentation of International Law' (2008) 42(1) Journal of World Trade 205.

[52] Morley, above n 4, 15 [internal marks omitted] citing T Levitt, The Marketing Imagination (Collier-Macmillan, 1983) 28.

[53] Article 18 ICCPR (1966) and Art 9 ECHR (1950).

[54] Article 19 ICCPR (1966) and Art 10 ECHR (1950).

[55] Article 26 ICCPR (1966) and Art 14 ECHR (1950).

[56] Potentially relevant group rights are 'using the native language, running their own schools, benefiting from access to other services provided by the group for the group, and participating in the political and economic affairs of the State': Gudmundur Alfredsson, 'Minority Rights and a New World Order' in Donna Gomien (ed) Broadening the Frontiers of Human Rights (Scandinavian University Press, 1993) 55, 62f..

[57] Council of Europe Framework Convention for the Protection of National Minorities (1995) and the European Charter for Regional or Minority Languages (1992).

[58] Alfredsson, above n 55, 65ff.

[59] Leyla Sahin v Turkey App No 44774/98, Grand Chamber (10 November 2005) para 108: 'Pluralism, tolerance and broadmindedness are hallmarks of a 'democratic society'. Although individual interests must on occasion be sub-ordinated to those of a group, democracy does not simply mean that the views of a majority must always prevail...'

[60] Leyla Sahin v Turkey App No 44774/98, Grand Chamber (10 November 2005) para 109.

[61] By the same token a 'European consensus' standard has meant that States have not been entitled to criminalise homosexual behaviour despite their 'domestic context': Dudgeon v UK A 45 (1981) 4 EHRR 149; Norris v Ireland A 142 (1988) 13 EHRR 186; Modinos v Cypros A 259 (1993) 16 EHRR 485. And neither was France, despite the historic context, entitled to criminalise revisionist speech (short of Holocaust denials) in the form of a defence of Marshal Petain, a collaborator with the Nazi regime: Lehideux and Isorni v France (1998-VII) 30 EHRR 665. 
[62] Rachel F Lewis, 'The 'death' of state multiculturalism: examining political discourse in post-2010 Europe' 6th Global Conference 'Interculturalism, Meaning and Identity' (Lisbon, March 2013) http://www.inter-disciplinary.net/at-the-interface/wp-

content/uploads/2013/02/Lewis2.pdf .

[63] Morley, above n 4, 7.

[64] Note 'nationalism' has been used both in favour of diversity (in response to the homogenising effect from the outside) and against diversity (in response to multiculturalism internally).

[65] This explains why the internet which has piggy-backed on the telephone infrastructure is legally significantly more problematic than the equally transnational telephone.

[66] Debora L Spar, Ruling the Waves: Cycles of Discovery, Chaos, and Wealth from the Compass to the Internet (Harcourt, 2001) 12ff.

[67] Ibid.

[68] Morley, above n 4, 25.

[69] While States have a right to make and apply laws to activities and persons outside their territory, they have no right to take any enforcement actions outside their territory:

enforcement jurisdiction is strictly territorial: 'The law may very well decide to cast its shadows beyond its borders; the judge may well have a voice so loud that, speaking in his house, his condemnations are head outside; the read of the police offer is only as long as his arm... he is a constable only at home.' Claude Lombois, Droit Penal International (2nd ed, Paris: Daloz, 1979) 536, cited in Pierre Trudel, 'Jurisdiction over the Internet: A Canadian Perspective' (1998) 32 The International Lawyer 1027, 1047. '

[70] For a historical account of the emergence of this romanticised image, see Philippe Aries, Centuries of Childhood (Libraire Plon, 1960) 126, commenting on the 17th century: 'A new concept of childhood had appeared, in which the child, on account of his sweetness, simplicity and drollery, became a source of amusement and relaxation for the adult.'

[71] Victoria Ward, Christopher Williams, 'Teenagers quizzed over links to international computer hacking ring faces extradition to US' (21 July 2011) The Telegraph http://www.telegraph.co.uk/news/uknews/crime/8650129/Teenager-quizzed-over-links-tointernational-computer-hacking-ring-faces-extradition-to-US.html

[72] Catherine Arcabascio, 'Sexting and Teenagers: OMG RU Going 2 Jail?' (2010) 16 Richmond Journal of Law and Technology 10; see also Xiaolu Zhang-Coenen, 'Parents Judging Parents - the Significance of Parental Responsibility and Violent Video Game Regulation' (2012) 18(5) Computer and Telecommunications Law Review 139.

[73] McDermott, above 22, 20.

[74] In Scotland the Criminal Justice and Licensing Act 2010 raised the age of criminal prosecution from 8 to 12 . 
[75] Don Cipriani, Children's Rights and the Minimum Age of Criminal Responsibility (Ashgate, 2009) Chapter 5.

[76] Laurence Lee, 'Young killers shown compassion' (30 June 2000) BBC News http://news.bbc.co.uk/1/hi/programmes/correspondent/803151.stm

[77] BBC 'A death that shocked the nation' (16 December 1999) BBC News http://news.bbc.co.uk/1/hi/uk/297023.stm

[78] Erwin James, Ian MaxDougall, 'The Norway town that forgave and forgot its child killers' (20 March 2010) The Guardian http://www.theguardian.com/theguardian/2010/mar/20/norway-town-forgave-child-killers .

[79] High Cunnigham, The Invention of Childhood (London: BBC Books, 2006) 24.

[80] Don Cipriani, Children's Rights and the Minimum Age of Criminal Responsibility (Ashgate, 2009) $\mathrm{Ch} 4$ on the historical influences that explain national variations.

[81] Nicola Lacey, 'Legal Construction of Crime' in Mike Maguire, Rod Morgan, Robert Reiner (ed), The Oxford Handbook of Criminology (4th ed, OUP, 2007) 179, 192, see also 189f.

[82] In England and Wales the very children that are old enough to be criminally responsible would be too young to enter into most contracts (18), vote (18), marry (16), drive (17), have sex (16), be served alcohol in a pub (18) or watch adult-rated movies (18).

[83] Spain is about to raise the age of sexual consent to 16. Stephen Burgen, 'Spain raises age of consent from 13 to 16' (4 September 2013) The Guardian http://www.theguardian.com/world/2013/sep/04/spain-raises-age-of-consent .

[84] For example, according to Art 18 of the Convention on the Protection of Children against Sexual Exploitation and Sexual Abuse (2007) each Party shall decide the age below which it is prohibited to engage in sexual activity with a child. See also text accompanying n 25 and 26.

[85] Council Framework Decision of 13 June 2002 on the European Arrest Warrant and the Surrender Procedure between Member States (2002/584/JHA)

[86] Lacey, above n 80, 193.

[87] Lacey, above n 80, 194.

[88] Although arguably a moderated response by the criminal justice system is in fact designed to be protective of these 'criminal' children and may serve their needs more effectively than any response outside that system.

[89] John Stuart Mill, On Liberty (1859, 2nd ed, London: John W Parker and Son) 134ff; although - as a sidenote - Mill had very different ideas for barbarians: 'To suppose that the same international customs, and the same rules of international morality, can obtain between one civilized nation and another, and between civilized nations and barbarians, is a 
grave error, and one which no statesman can fall into...' John Stuart Mill, Dissertations and Discussions: Political, Philosophical, and Historical Vol 3 (New York: Henry Holt, 1882) 252.

[90] Lacey above n 80, 184, see also Bernard E Harcourt, 'The Collapse of the Harm Principle' 90 (1998) Journal of Criminal Law and Criminology 109; Paddy Hillyard, Christina Pantazis, Steve Tombs, Dave Gordon (eds), Beyond Criminology: Taking Harm Seriously (Pluto Press, 2004).

[91] Lacey, above n 80, 184.

[92] Quoted in Robin Headlam Wells, Johnjoe McFadden (eds), Human Nature: Fact and Fiction (Continuum, 2006) 53f.

[93] Livingstone, above n 22, 22; the authors allude to a difference between 'upset' and 'harmful' in the following: 'Although public concern over online sexual content is justified, the extent of children's exposure should not be exaggerated, and nor should it be assumed that all children are upset or harmed by such exposure - the present findings do not support some of the moral panics surrounding this issue.'(23).

[94] See also Livingstone, above n 22, 23, notes: 'Risk and harm are not the same - older children and boys encounter more sexual content, but younger children and girls are more upset when they do encounter this.'

[95] S Tanya Byron, Safer Children in a Digital World - The Report of the Byron Review (2008) Department of Education, https://www.education.gov.uk/publications/eOrderingDownload/DCSF-00334-2008.pdf, para 3.38 .

[96] BBC, 'UK fears over film ratings idea' (6 May 2004) BBC News

http://news.bbc.co.uk/1/hi/entertainment/3688979.stm

[97] See e.g. the mission statement by the BBFC: 'protect the public, and especially children, from content which might raise harm risks', http://www.bbfc.co.uk/aboutbbfc/our-mission.

[98] Christian Buttner, 'The Protection of Minors Against Harmful Media Content in Europe - How European Film Classifiers View Childhood and Adolescence' (2005) 1 Nordicom Review 121, http://www.nordicom.gu.se/common/publ_pdf/180_121-130.pdf.

[99] Andreas Wiseman, 'BBFC to adopt tougher line on unclassified video content, Black Swan most complained about film in cinemas last year' (11 July 2012) SreenDaily http://www.screendaily.com/news/uk-ireland/bbfc-to-adopt-tougher-line-on-unclassifiedvideo-content-black-swan-most-complained-about-film-in-cinemas-lastyear/5044258.article [internal references omitted]; Note too, how standards change over time, Audrey Ward, 'UK film censor takes softer view on drugs' (24 June 2009) SreenDaily http://www.screendaily.com/news/uk-ireland/uk-film-censor-takes-softer-view-ondrugs/5002800.article. 
[100] Buttner, above n 97, 121f.

[101] See above.

[102] PEGI, About PEGI?, http://www.pegi.info/en/index/id/28/.

[103] See Council of the EU, Council Resolution of 1 March 2002 on the protection of consumers, in particular young people, through the labelling of certain video games and computer games according to age group (2002/C65/02). See also the industry-driven 'CEO Coalition' (2011) and its self-regulatory online framework.

[104] Sections 40, 41 of the Digital Economy Act 2010 and the Video Recording (Labelling) Regulations 2012. PEGI launched PEGI Online in 2007 with the support of the European Commission. See also, UK Parliament (Philip Ward), Classification of Video Games - Briefing Paper (8 March 2013) Ref: SN/HA/6334, http://www.parliament.uk/briefing-papers/SN06334.pdf .

$[105]$ See text accompanying n 51.

[106] Christopher Williams, 'BBFC has persuasion job over online ratings' (14 March 2013) The Telegraph http://www.telegraph.co.uk/technology/internet/9929070/BBFC-haspersuasion-job-over-online-ratings.html .

[107] Note PEGI Online was launched in 2007 with the support of the European Commission.

[108] Explanatory Memorandum to the Video Recordings (Labelling) Regulations 2012 (2012 No1767), para 3.1.

[109] The maximum punishment for selling a non-exempt video game to someone who does not meet the age classification is up to six months in prison and a fine of up to $£ 5,000$. Supplying a non-exempt game without an age-rating will be punishable by up to two years in prison and an unlimited fine. Ward, above n 103, 5.

[110] There has also been discussion of removing the exemption under the Video Recordings Act 1984 with regard to 'music, sports, religious or educational videos'. Department for Culture, Media \& Sport (DMCA) Consultation on Exemptions to the Video Recordings Act and on Advertising in Cinemas - Government Response (May 2013).

[111] The Video Recording Act 1984 originally mainly focused on films is now extended to previously exempt video games.

[112] Christopher Williams, 'BBFC has persuasion job over online ratings' (14 March 2013) The Telegraph http://www.telegraph.co.uk/technology/internet/9929070/BBFC-haspersuasion-job-over-online-ratings.html

[113] For example, under the Licencing Act 2003 licences to show films given to cinemas by local authorities would be issued in according with the recommendations of the BBFC. 
[114] At the forefront ISPs: 'The four major ISPs have signed a Code of Practice which ensures that all new customers are offered parental controls and they are beginning to make the same offer to existing customers as well. UKCCIS Ministers consulted last summer on what more could be done to ensure parents have the tools and information they need to make the choices that are right for them and their families in relation to accessing content online.' DCMS, above n 109, para 75.

[115] DCMS, above n 109, para 10.

[116] BBFC, Annual Report and Accounts 2012 (2013) noting a 40\% jump in online-only classification.

[117] Andreas Wiseman, 'BBFC: "paradigm shift in relation to online classification"' (11 July 2013) SrceenDaily http://www.screendaily.com/news/distribution/bbfc-paradigm$\underline{\text { shift-in-relation-to-online-classification/5058236.article }}$

[118] See for example, OECD, Recommendation of the Council on the Protection of Children Online (16 February 2012) C(2011)155.

[119] BBFC, New research reveals kids' summer of illegal downloads is a disturbing sight for young eyes (8 August 2013)

http://www.bbfc.co.uk/about-bbfc/media-centre/new-research-reveals-kids-summer-illegaldownloads-disturbing-sight-young .

[120] John Micklethwait and Adrian Wooldridge, The Fourth Revolution (Penguin, 2014)

[121] Diamond, above n 1, 206f

[122] Kohl, above n 9, Ch 4.

[123] Kohl, above n 9.

[124] See Roger Brownsword, 'The Shaping of Our On-Line Worlds: Getting the Regulatory Environment Right' (2012) 20 (4) International Journal of Law and Information Technology 249, 251 where the authors refers to a third phase in online/offline governance in which the 'off-line world has been absorbed into a pervasive on-line environment.'

[125] Morley, above n 4, 8, quoting Kobena Mercer, 'Welcome to the Jungle' in J Rutherford (ed), Identity: Community, Culture, Difference (Lawrence \& Wishart, 1990)

[126] Morley, above n 4, 24. 